\title{
Bone and Cellular Immune System of Multiparous Sows are Insensitive to Ovariectomy and Nutritive Calcium Shortage
}

Authors

Affiliations
W. Sipos ${ }^{1}$, E. Kralicek ${ }^{1}$, M. Rauner ${ }^{2}$, C. J. Duvigneau ${ }^{3}$, H. L. Worliczek ${ }^{4}$, D. Schamall ${ }^{5}$, R. T. Hartl ${ }^{3}$, I. Sommerfeld-Stur ${ }^{6}$, E. Dall'Ara ${ }^{7}$, P. Varga ${ }^{7}$, H. Resch ${ }^{8}$, I. Schwendenwein ${ }^{9}$, P. Zysset ${ }^{7}$, P. Pietschmann ${ }^{5}$

Affiliation addresses are listed at the end of the article
Key words

osteoporosis

- osteoimmunology

pig received 07.12 .2010

accepted 06.04.2011

\section{Bibliography}

DOI http://dx.doi.org/

10.1055/s-0031-1277154

Published online:

May 9, 2011

Horm Metab Res 2011;

43: 404-409

(c) Georg Thieme Verlag KG

Stuttgart · New York

ISSN 0018-5043

\section{Correspondence}

Univ.Prof. Dr. W. Sipos,

Dipl. ECPHM

Clinic for Swine

University of Veterinary

Medicine Vienna

Veterinärplatz 1

1210 Vienna

Austria

Tel.: + 43/1/25077 5206

Fax: + 43/1/25077 5297

wolfgang.sipos@vetmeduni.ac.at

\section{Abstract}

$\nabla$

Research in osteoporosis, which is a complex systemic disease, demands suitable large animal models. In pigs, most research has been done in growing minipigs, which probably are not ideal models for postmenopausal osteoporosis. Therefore, our aim was to analyze the effects of ovariectomy (OVX) and nutritive calcium shortage on multiparous Large White sows. 32 animals were randomly assigned to 4 groups in a cross design with OVX vs. sham and physiological calcium supplementation $(0.75 \%$ calcium) vs. dietary calcium shortage $(0.3 \%$ calcium). The observation period was 10 months with blood sampling every 2 months for hematological, immunological, and biochemical bone

\section{Introduction}

$\nabla$

Osteoporosis is a complex systemic disease [1]. In vitro models are not sufficient to analyze systemic effects, thus, there is a great need for suitable animal models. Rodent models, which have several advantages in terms of laboratory management, are well established and have been widely used in osteoporosis research. However, the US Food and Drug Administration demands also the use of large animal models, mainly due to biomechanical issues, besides rats in preclinical testing of antiosteoporotic substances with an experimental time frame of 12 months when using rats and 16 months when using larger species. According to FDA regulations, valid animal models have to develop an osteoporotic phenotype either spontaneously or after ovariectomy (OVX), which mimics postmenopausal estrogen deficiency [2].

Pigs as well as sheep are among the most frequently used large animal species in osteoporosis research. Although there are a lot of similarities marker measurements. At the termination of the experiment, animals were sacrificed. Samples of trabecular bone of distal radius, proximal tibia, and sixth lumbar vertebra were subjected to micro-computed tomography imaging and ashed afterwards. Dual X-ray absorptiometry scans of the proximal femora were performed with prepared bones being placed in a water bath for mimicking soft tissue. Analyses of bone marker and cytokine profile kinetics, distribution of leukocyte subpopulations, and morphometrical and densitometrical analyses showed no evidence of any impact of OVX or calcium shortage. In conclusion, the skeleton of adult sows of a conventional breed is seemingly protected from effects of OVX and calcium shortage.

of diverse porcine organ systems to their human analogues, the pig's usefulness as an osteologic model species is still not entirely clear. However, even though porcine femoral compact bone is predominantly plexiforme, it is converted to well-developed osteonal bone earlier than in sheep [3]. Peak bone mass is obtained with an age of 2-3 years. The main body of investigations in this area of research was performed using growing minipigs, which, however, might not appropriately reflect the situation of the postmenopausal osteoporotic woman due to their juvenile age and dwarfism. On the other hand, minipigs achieve sexual maturity earlier than conventional pigs and thus OVX may induce the desired phenotype earlier than in conventional sows. OVX in 10 months old minipigs resulted in a $6 \%$ decrease in bone mineral density (BMD), $15 \%$ in bone volume (BV), and $13 \%$ in trabecular number, and an increase of $15 \%$ in trabecular separation after 6 months, whereas OVX in combination with a mild nutritive calcium shortage $\left(0.75 \% \mathrm{Ca}^{2+}\right)$, which had been started already at 
an age of 4 months, led to a $10 \%$ reduction in vertebral BMD and significant increases in final erosion depth and vertebral marrow star volume [4]. A study investigating multiparous sows being fed a standard diet $\left(1.5 \% \mathrm{Ca}^{2+}\right)$ showed moderate and transient increases in plasma PTH, calcitriol and bone-specific alkaline phosphatase (BAP) levels over a time span of 1 year after OVX [5]. However, no significant changes concerning bone chemistry and histomorphometry were observed. Consequently, we were interested in evaluating the impact of OVX in combination with pronounced calcium shortage on bone metabolism, bone microstructure, and immunological parameters in multiparous conventional sows in contrast to the minipigs analyzed by other authors. Analysis of immunological parameters was included as osteoporosis as a systemic disease is known to be correlated with a proinflammatory reactivity of the immune system [6].

\section{Materials and Methods}

$\nabla$

\section{Animals and group assignment}

32 multiparous Large White sows aged $33.5 \pm 9.6$ months in the mean and all of them approximately 2 months post partum and thus not lactating for over 5 weeks were allocated equally to 4 groups to compare the effects of OVX and dietary calcium shortage: (I) OVX, $0.75 \% \mathrm{Ca}^{2+}$, (II) OVX, $0.3 \% \mathrm{Ca}^{2+}$, (III) sham-OVX, $0.75 \% \mathrm{Ca}^{2+}$, and (IV) sham-OVX, $0.3 \% \mathrm{Ca}^{2+}$. Ovariectomy was performed from the left flank under full anesthesia with an IV bolus of ketamine and azaperone. Post-surgical treatment was done with enrofloxacine, metamizole, and local oxytetracycline spray. Sows were housed as groups of 5 or 6 in a separate stable under standard conditions. Diets were mainly based on barley, soy, and lignocellulose and produced by a farm animals' feed company (Biomin, Herzogenburg, Austria). One diet contained the usually supplemented calcium levels for nongestating sows, that is, $0.75 \%$, and the other one was a low calcium diet containing $0.3 \%$. For detailed composition of diets see $\odot$ Table 1. Blood samples were collected by venipuncture of the jugular vein every 2 months. All animal experiments were approved by the institutional and the governmental ethics committees. The experiment was terminated after 10 months.

\section{Biochemical bone markers and hormones}

Serum levels of following bone metabolism markers were determined by commercially available ELISA kits, which have been validated also for pigs $[7,8]$ : receptor activator of nuclear factor-кВ ligand (ampli-sRANKL ELISA, Biomedica, Vienna, Austria), calcitriol (25-OH-Vitamin D direct ELISA, Immundiag-

Table 1 Composition of diets (per kg)

\begin{tabular}{|lll|} 
& Low-calcium diet & Physiological diet \\
\hline ME (MJ) & 11.1 & 11.1 \\
\hline Crude protein (\%) & 13.0 & 13.0 \\
\hline Crude fat (g) & 22.0 & 22.0 \\
\hline Crude fiber (g) & 102.0 & 102.0 \\
\hline Vit A (IU) & 9900 & 9900 \\
\hline Vit $D_{3}($ IU) & 1320 & 1320 \\
\hline Vit E (mg) & 70 & 70 \\
\hline $\mathrm{Ca}(\mathrm{g})$ & 3.0 & 7.5 \\
\hline $\mathrm{P}(\mathrm{g})$ & 3.8 & 6.0 \\
\hline $\mathrm{Na}(\mathrm{g})$ & 1.7 & 1.7 \\
\hline $\mathrm{Cu}(\mathrm{mg})$ & 16.5 & 16.5 \\
\hline
\end{tabular}

nostik, Bensheim, Germany), PTH (Porcine Intact PTH ELISA, Immutopics, San Clemente, CA, USA), bone specific alkaline phosphatase (Metra ${ }^{\circledR}$ BAP ELISA, Qidel Corporation, San Diego, CA, USA), osteocalcin (Metra ${ }^{\circledR}$ Osteocalcin ELISA, Qidel Corporation), CICP (Metra ${ }^{\circledR} \mathrm{CICP}$ ELISA, Qidel Corporation), pyridinoline (Metra ${ }^{\circledR}$ Serum PYD ELISA, Qidel Corporation), and crosslaps (Serum CrossLaps ${ }^{\circledR}$ ELISA, Immunodiagnostic Systems, Frankfurt/ Main, Germany). For measurement of serum estrogens, a home made enzyme immunoassay for the detection of estron and $17 \beta$ estradiol was applied [9]. The low detection limit of this test of $2 \mathrm{pg}$ of estrogens $/ \mathrm{ml}$ is superior to the one of commercial systems.

\section{Hematological and immunological analyses}

Hematological analyses were performed out of EDTA-blood using an ADVIA ${ }^{\circledR} 120$ (Siemens Health Care Diagnostics, Deerfield, IL, USA) with veterinary software adapted for pigs. Cytokine levels were determined at both the genomic as well as the protein levels. For preparation of total RNA out of peripheral blood mononuclear cells (PBMCs), the pellet was suspended in $1.2 \mathrm{ml}$ of hemolysis buffer ( $140 \mathrm{mM} \mathrm{NH}_{4} \mathrm{Cl}, 17 \mathrm{mM}$ Tris, $\left.\mathrm{pH} 7.2\right)$ and incubated at $37^{\circ} \mathrm{C}$ for $15 \mathrm{~min}$. Samples were then centrifuged and supernatant was removed. Pelleted white blood cells were resuspended in $1 \mathrm{ml}$ of TriReagent ${ }^{\circledR}$ (Molecular Research Center, Inc., Cincinnati, USA) and frozen at $-80^{\circ} \mathrm{C}$ until analysis. Total RNA was extracted in accordance to the manufacturers' protocol. Integrity, quantity, and contamination with genomic DNA were analyzed on the Agilent BioAnalyzer 2100 (Agilent Technologies, Palo Alto, USA) using the RNA6000 Nano LabChip ${ }^{\circledR}$ kit (Agilent). $1 \mu \mathrm{g}$ of total RNA was used to synthesize cDNA using Superscript ${ }^{\mathrm{TM}}$ II RNAse H-reverse transcriptase (200U/reaction; Invitrogen, Carlsbad, USA) and anchored oligo-dT-primers (3.5 $\mu \mathrm{M}$ final concentration). To check the generation of amplifiable cDNA in the reverse transcription, a conventional PCR step was performed using GAPDH specific primers. The profiling of the expressions of the cytokine genes interleukin (IL)-1, IL-2, IL-4, IL-6, IL-10, interferon (IFN)- $\gamma$, tumor necrosis factor (TNF)- $\alpha$, as well as inducible NO synthase (iNOS) and heme oxygenase (HO)-1 and the 3 housekeeping genes cyclophilin, GAPDH, and $\beta$-actin was performed by means of real-time triplex PCR, using $\operatorname{TaqMan}^{\circledR}$ probes and specific primer pairs on the iCycler $\mathrm{iQ}^{\circledR}$ (Bio-Rad, Hercules, USA) as described by others [10].

Intracellular cytokine expressions of IL-1 $\beta$, IL-2, IL-4, IL-6, IL-10, IL-12p35, TNF- $\alpha$, and IFN- $\gamma$ were measured in PBMCs as described previously using a FACSAria ${ }^{\circledR}$ flow cytometer (Becton Dickinson, San Jose, CA, USA) [11]. Subpopulations of white blood cells including monocytes, plasmacytoid dendritic cells, $\mathrm{B}$ cells, naïve, activated, and memory $\mathrm{T}$ helper cells, regulatory $\mathrm{T}$ cells, cytotoxic $\mathrm{T}$ lymphocytes, $\gamma \delta$-T cells, and natural killer cells were discriminated and quantified by FACS. Antibody clones used for distinguishing cell markers as well as surface marker co-expression profiles used for identification of antigen presenting cells and lymphocyte subpopulations were the same as used by Sipos et al. [11].

\section{$\mu C T$ and DXA analyses of selected bone sites}

The following bone sites were considered for $\mu \mathrm{CT}$ imaging and analysis: sixth lumbar vertebra (L6), proximal tibia, and distal radius. Bones were frozen at $-80^{\circ} \mathrm{C}$ until preparation. After freeing bones from soft tissue, a transverse section was obtained from each site of interest and from each animal (diamond band saw, $300 \mathrm{CP}$, Exakt GmbH, Germany). Then, one trabecular bone cylinder of $8 \mathrm{~mm}$ in nominal diameter and $12 \mathrm{~mm}$ in nominal 
length was extracted from each section using a diamond coated coredrill. The biopsies were immersed in saline solution, freed of air bubbles by application of vacuum and scanned with $12 \mu \mathrm{m}$ resolution using a $\mu \mathrm{CT} 40$ system (ScancoMedical AG, Switzerland) with $70 \mathrm{kV}, 114 \mathrm{~mA}$, and $200 \mathrm{~ms}$ integration time. The region of interest was restricted to an inner cylinder with $7 \mathrm{~mm}$ diameter and $11.5 \mathrm{~mm}$ length via contouring to exclude peripheral artefacts. Morphological analysis of each biopsy was performed with the inbuilt software tools provided by the manufacturer (IPL). The images were filtered using a Gaussian filter ( $\operatorname{sigma}=0.7$, support $=1$ ) and segmented using a global threshold value corresponding to $20 \%$ of the maximum gray value intensity. A standard evaluation protocol was used to compute the histomorphometric parameters from the segmented images. 2 biopsies containing a significant part of the growth plate were excluded from the analysis.

DXA scans of femoral neck, trochanter, and the total region including head, neck, and trochanter were performed using a Lunar iDXA ${ }^{\circledR}$ bone densitometer with prepared femora being placed in a water bath for mimicking soft tissue.

\section{Bone ash analysis}

The volume of each trabecular bone biopsy used for $\mu \mathrm{CT}$ analysis was calculated out of 5 consecutive measurements of height and diameter. Ashing was performed for $24 \mathrm{~h}$ at $650^{\circ} \mathrm{C}$ and ash weight was measured after a consecutive cooling down phase at room temperature for another $24 \mathrm{~h}$.

\section{Statistics}

Statistical evaluation was performed by PASW-Statistic Software, version 17.0. 2. All variables were tested for normal distribution. As most of them fulfilled the requirements for parametric evaluation, ANOVA was applied for group comparisons. In cases where normal distribution was excluded, a Kruskal-Wallis test was used. For post hoc analysis, a Bonferroni test was applied.

\section{Results}

$\nabla$

\section{Hematology and cellular immune parameters}

Hematological analyses including FACS-based analysis of the distribution of antigen-presenting cell and lymphocyte subpopulations as well as cytokine profile kinetics revealed no meaningful trends over the course of the trial. Also, no differences could be observed between the 4 groups at either time point. Instead, cytokine titers or cell numbers of immunocyte subpopulations were found within the respective reference ranges [11] (data not shown). They only slightly undulated from one time point of measurement to the next and thus gave no evidence of any OVX- or calcium shortage-induced change in hematological or immune status.

\section{Biochemical bone markers and hormones}

Mean values and standard deviations of investigated biochemical bone markers of the last sampling session are given in $\odot$ Table 2. As with hematological and cellular immune parameters, levels were only slightly undulating without any trend of either increasing or decreasing titers for each of the parameters over time. Results of group 3, which was the control group, can be considered as physiological reference values.

Serum estrogens (estron and $17 \beta$-estradiol) were measured at baseline, 1 month after OVX, and at the termination of the experiment. At baseline, estrogens were detectable in only 13 out of 32 animals, giving evidence of 13 sows being in estrus at that time point. 1 month post OVX, estrogens were detectable in $6 / 16$ ovariectomized sows as compared to $10 / 16$ non-ovariectomized animals. At the end of the experiment, only 1 ovariectomized sow had a detectable estrogen titer $(4.6 \mathrm{pg} / \mathrm{ml})$, whereas estrogen titers of 7 non-ovariectomized sows were exceeding the detection limit.

\section{Morphological and densitometrical analyses}

Also morphological as well as densitometrical analyses gave no evidence of any impact of OVX or calcium shortage on bone microstructure or density ( $\odot$ Table 3, 4). To better demonstrate the uniformity of trabecular bone microstructure of each anatomical site between groups, 2D $\mu \mathrm{CT}$ images of all investigated bone sites of reference animals of each group are given in 0 Fig. 1.

\section{Discussion and Conclusions}

To date, mostly minipigs are used as large animal biomedical model species. Pure bred minipigs are expensive and have distinct ontogenetic and physiologic features when compared to conventional pigs [12]. These include earlier sexual maturity and a chondrodystrophic phenotype, which is common to most minipig strains. Additionally, most experiments in osteoporosis research were performed with growing minipigs, which may be a drawback when trying to extrapolate data to the situation of postmenopausal women. Therefore, our aim was to investigate the suitability of multiparous conventional sows as a model in osteoporosis research. We analyzed the effects of calcium shortage and OVX over a time span of 10 months. We chose this time frame because changes in bone metabolism as well as bone mass and architecture due to OVX and calcium shortage could have

Table 2 Biochemical bone marker levels acquired at the termination of the experiment (10 months post OVX)

\begin{tabular}{|c|c|c|c|c|c|c|c|c|c|}
\hline & \multicolumn{2}{|c|}{ Group 1 (OVX) } & \multicolumn{2}{|c|}{ Group 2 (OVX, low Ca) } & \multicolumn{2}{|c|}{ Group 3 (Sham) } & \multicolumn{2}{|c|}{ Group 4 (Sham, low Ca) } & \multirow[b]{2}{*}{ p-Value } \\
\hline & Mean & SD & Mean & SD & Mean & SD & Mean & SD & \\
\hline sRANKL (pmol/l) & 0.7 & 0.6 & 0.6 & 0.7 & 0.5 & 0.5 & 0.4 & 0.6 & 0.89 \\
\hline $\mathrm{BAP}(\mathrm{E} / \mathrm{I})$ & 13.5 & 4.2 & 16.5 & 2.3 & 14.7 & 5.7 & 15.7 & 5.2 & 0.55 \\
\hline $\mathrm{OC}(\mathrm{ng} / \mathrm{ml})$ & 194.7 & 139.3 & 304.2 & 88.6 & 236.2 & 150.4 & 192.7 & 106.8 & 0.34 \\
\hline $\mathrm{CICP}(\mathrm{ng} / \mathrm{ml})$ & 40.0 & 38.3 & 71.2 & 109.7 & 32.9 & 53.2 & 88.7 & 74.2 & 0.54 \\
\hline PYD (nmol/l) & 8.5 & 0.9 & 8.0 & 0.8 & 8.5 & 0.4 & 8.4 & 0.6 & 0.55 \\
\hline Crosslaps (ng/ml) & 1.5 & 0.9 & 2.0 & 1.3 & 0.9 & 0.7 & 0.9 & 0.6 & 0.16 \\
\hline PTH (pg/ml) & 16.3 & 30.6 & 19.5 & 37.1 & 23.2 & 19.1 & 34.6 & 33.8 & 0.40 \\
\hline $\mathrm{VitD}_{3}(\mathrm{nmol} / \mathrm{I})$ & 170.1 & 101.8 & 157.5 & 106.6 & 212.9 & 19.3 & 123.7 & 92.9 & 0.47 \\
\hline
\end{tabular}


Table 3 Bone mineral content at 10 months post OVX

\begin{tabular}{|c|c|c|c|c|c|c|c|c|c|}
\hline & \multicolumn{2}{|c|}{ Group 1 (OVX) } & \multicolumn{2}{|c|}{ Group 2 (OVX, low Ca) } & \multicolumn{2}{|c|}{ Group 3 (Sham) } & \multicolumn{2}{|c|}{ Group 4 (Sham, low Ca) } & \multirow[b]{2}{*}{ p-Value } \\
\hline & Mean & SD & Mean & SD & Mean & SD & Mean & SD & \\
\hline \multicolumn{10}{|l|}{$\operatorname{DXA}\left(\mathrm{g} / \mathrm{cm}^{2}\right)$} \\
\hline Neck & 1.47 & 0.08 & 1.56 & 0.16 & 1.48 & 0.11 & 1.43 & 0.15 & 0.34 \\
\hline Trochanter & 1.59 & 0.14 & 1.58 & 0.09 & 1.76 & 0.2 & 1.6 & 0.34 & 0.51 \\
\hline Total & 1.67 & 0.09 & 1.67 & 0.05 & 1.76 & 0.09 & 1.62 & 0.26 & 0.54 \\
\hline \multicolumn{10}{|c|}{ Bone ash values $\left(\mathrm{mg} / \mathrm{cm}^{3}\right)$} \\
\hline Radius & 380.0 & 61.0 & 393.7 & 108.9 & 393.7 & 49.1 & 346.2 & 45.5 & 0.65 \\
\hline Tibia & 344.3 & 95.4 & 339.3 & 113.8 & 312.0 & 94.5 & 282.7 & 78.9 & 0.65 \\
\hline Lumbar vertebra & 394.7 & 55.3 & 374.9 & 60.7 & 394.3 & 65.3 & 385.2 & 39.4 & 0.91 \\
\hline
\end{tabular}

Table $4 \mu \mathrm{CT}$ data of respective bone sites at 10 months post OVX

\begin{tabular}{|c|c|c|c|c|c|c|c|c|c|}
\hline \multirow[t]{2}{*}{ Bone site } & \multicolumn{2}{|c|}{ Group 1 (OVX) } & \multicolumn{2}{|c|}{ Group 2 (OVX, low Ca) } & \multicolumn{2}{|c|}{ Group 3 (Sham) } & \multicolumn{2}{|c|}{ Group 4 (Sham, low Ca) } & \multirow[b]{2}{*}{ p-Value } \\
\hline & Mean & SD & Mean & SD & Mean & SD & Mean & SD & \\
\hline \multicolumn{10}{|l|}{ Radius } \\
\hline BMD apparent $\left(\mathrm{mg} / \mathrm{cm}^{3}\right)$ & 357.5 & 68.4 & 404.3 & 111.0 & 376.0 & 58.2 & 341.2 & 43.1 & 0.50 \\
\hline BMD tissue $\left(\mathrm{mg} / \mathrm{cm}^{3}\right)$ & 1048.1 & 40.9 & 1093.3 & 120.6 & 1047.8 & 19.9 & 1075.6 & 24.6 & 0.58 \\
\hline BV/TV (\%) & 0.327 & 0.058 & 0.349 & 0.090 & 0.339 & 0.048 & 0.304 & 0.038 & 0.63 \\
\hline BS/BV (\%) & 12.594 & 2.160 & 12.062 & 2.374 & 12.504 & 1.932 & 12.725 & 1.050 & 0.93 \\
\hline Tb.N (/mm) & 2.019 & 0.212 & 2.031 & 0.234 & 2.087 & 0.104 & 1.922 & 0.123 & 0.52 \\
\hline Tb. Th (mm) & 0.162 & 0.024 & 0.171 & 0.032 & 0.162 & 0.024 & 0.158 & 0.013 & 0.81 \\
\hline Tb. Sp (mm) & 0.337 & 0.061 & 0.327 & 0.079 & 0.317 & 0.028 & 0.363 & 0.040 & 0.57 \\
\hline Degree of anisotropy & 2.303 & 0.286 & 2.184 & 0.439 & 2.142 & 0.301 & 2.429 & 0.198 & 0.44 \\
\hline ConnDens $\left(/ \mathrm{mm}^{3}\right)$ & 5.818 & 1.547 & 7.635 & 3.236 & 6.118 & 1.021 & 5.837 & 1.254 & 0.33 \\
\hline Structure model index & -0.439 & 0.276 & -0.448 & 0.693 & -0.472 & 0.289 & -0.053 & 0.351 & 0.34 \\
\hline \multicolumn{10}{|l|}{ Tibia } \\
\hline BMD apparent $\left(\mathrm{mg} / \mathrm{cm}^{3}\right)$ & 320.2 & 98.9 & 298.1 & 108.3 & 294.3 & 101.5 & 255.9 & 85.1 & 0.69 \\
\hline BMD tissue $\left(\mathrm{mg} / \mathrm{cm}^{3}\right)$ & 1073.9 & 44.2 & 1044.3 & 55.6 & 1086.0 & 25.8 & 1094.5 & 54.5 & 0.24 \\
\hline BV/TV (\%) & 0.291 & 0.086 & 0.282 & 0.096 & 0.264 & 0.090 & 0.238 & 0.068 & 0.70 \\
\hline BS/BV (\%) & 15.078 & 4.272 & 15.877 & 4.196 & 15.872 & 4.047 & 16.874 & 3.638 & 0.88 \\
\hline Tb. $\mathrm{N}(/ \mathrm{mm})$ & 2.040 & 0.175 & 2.074 & 0.235 & 1.969 & 0.200 & 1.920 & 0.228 & 0.54 \\
\hline Tb. Th (mm) & 0.141 & 0.035 & 0.134 & 0.039 & 0.133 & 0.035 & 0.123 & 0.030 & 0.84 \\
\hline Tb. Sp (mm) & 0.351 & 0.067 & 0.352 & 0.079 & 0.379 & 0.072 & 0.403 & 0.081 & 0.55 \\
\hline Degree of anisotropy & 1.820 & 0.376 & 1.880 & 0.307 & 1.917 & 0.315 & 1.841 & 0.424 & 0.96 \\
\hline ConnDens $\left(/ \mathrm{mm}^{3}\right)$ & 8.610 & 2.261 & 9.138 & 3.024 & 8.103 & 0.698 & 8.287 & 2.700 & 0.87 \\
\hline Structure model index & 0.144 & 0.530 & 0.132 & 0.727 & 0.299 & 0.641 & 0.450 & 0.622 & 0.77 \\
\hline \multicolumn{10}{|l|}{ L6 } \\
\hline BMD apparent $\left(\mathrm{mg} / \mathrm{cm}^{3}\right)$ & 367.3 & 65.1 & 347.9 & 80.2 & 399.8 & 53.2 & 383.6 & 38.2 & 0.53 \\
\hline BMD tissue $\left(\mathrm{mg} / \mathrm{cm}^{3}\right)$ & 1014.5 & 49.7 & 994.8 & 64.0 & 1036.4 & 12.7 & 1006.0 & 46.6 & 0.54 \\
\hline $\mathrm{BV} / \mathrm{TV}(\%)$ & 0.339 & 0.046 & 0.327 & 0.053 & 0.352 & 0.047 & 0.348 & 0.033 & 0.77 \\
\hline BS/BV (\%) & 13.706 & 2.656 & 15.014 & 1.813 & 13.159 & 2.135 & 14.300 & 1.270 & 0.44 \\
\hline Tb. $\mathrm{N}(/ \mathrm{mm})$ & 2.289 & 0.265 & 2.421 & 0.232 & 2.286 & 0.265 & 2.477 & 0.144 & 0.39 \\
\hline Tb. Th (mm) & 0.149 & 0.024 & 0.134 & 0.016 & 0.155 & 0.029 & 0.140 & 0.014 & 0.36 \\
\hline Tb.Sp (mm) & 0.292 & 0.045 & 0.281 & 0.049 & 0.286 & 0.041 & 0.263 & 0.023 & 0.66 \\
\hline Degree of anisotropy & 2.196 & 0.241 & 2.065 & 0.169 & 2.118 & 0.170 & 2.041 & 0.135 & 0.33 \\
\hline ConnDens $\left(/ \mathrm{mm}^{3}\right)$ & 3.902 & 1.354 & 4.332 & 1.358 & 4.027 & 1.247 & 3.989 & 1.297 & 0.93 \\
\hline Structure model index & -1.258 & 0.385 & -1.259 & 0.364 & -1.405 & 0.452 & -1.418 & 0.365 & 0.80 \\
\hline
\end{tabular}

been expected already within 6 months according to the available literature dealing with growing minipigs [4].

Interestingly, OVX and calcium shortage alone as well as in combination did not influence bone metabolism and microstructure. This was unexpected, as other authors observed increasing PTH, calcitriol, and BAP plasma levels, albeit transient and moderate, in sows of the same age group as the ones investigated here, although those were ovariectomized but fed a standard diet [5]. Nevertheless, these authors also did not find any significant changes concerning bone chemistry and histomorphometry. One reason for the observed dynamic rigidity, meaning the inability to respond to estrogen and calcium shortage, might be the notably high BMD of adult pigs, making efforts to artificially reduce bone mass and weakening bone a hardly achievable task. Lactating sows have to nourish litters of up to 13 piglets and thus produce large amounts of milk with $10-11 \mathrm{~kg}$ per day containing approximately $50 \mathrm{mmol} / \mathrm{l}$ calcium, which corresponds to a 14 times higher calcium concentration than human milk, consequently giving evidence of the intense need for huge calcium resources [13]. Despite these tremendous physiologic needs for calcium the skeletal apparatus has to function properly. This may provide some explanation for the peculiarities of bone physiology of adult sows.

In other ungulates investigated so far, that is, sheep, OVX alone reduces bone mass, which can be enforced by an additional nutritive calcium shortage. BMD of L5 and distal radius as evaluated by DXA was significantly changed after 6 months and the one of L4 1 year after OVX, whereas the proximal parts of femur, humerus, and tibia did not exhibit alterations to that extent [14]. However, MacLeay and colleagues [15] were not able to detect 


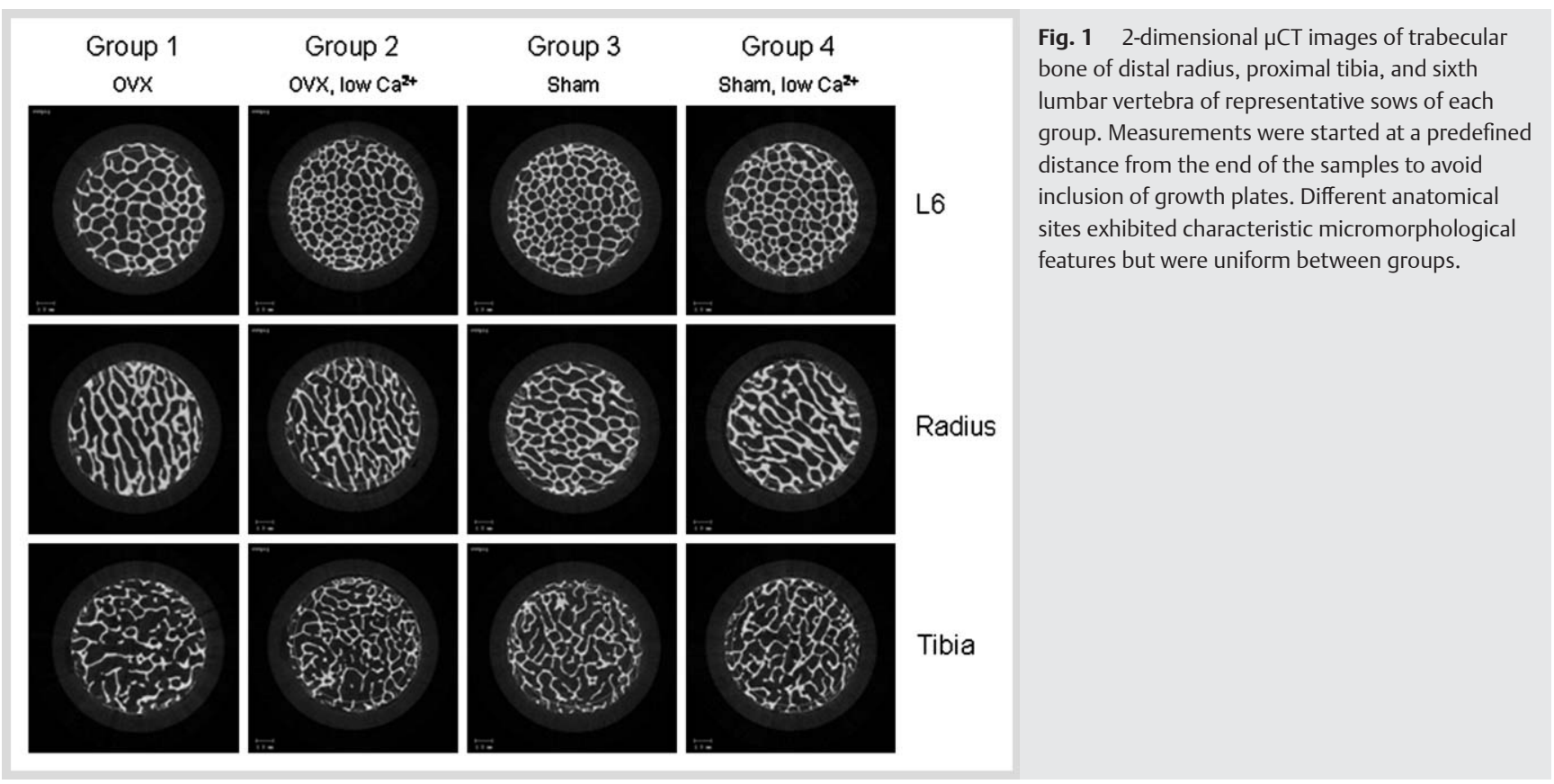

areal BMD changes in lumbar vertebrae in ovariectomized sheep 3 months after surgery. Another study showed a significantly decreased femoral but not lumbar vertebral BMD as well as significant effects on cortical bone parameters by 6 months after OVX [16]. The lesser effects of single OVX treatment on bone mass in sheep are discussed by their probable ability of extragonadal estrogen production, which has not been reported for pigs so far. Interesting and seemingly inconsistent with the hypothesis of extragonadal estrogen synthesis is the fact that sheep experience significant microarchitectural changes in vertebral cancellous bone (decreased BV/TV by approximately $30 \%$, trabecular thickness by $13 \%$, and increased trabecular separation by $46 \%$ ) 2 years after OVX and show significantly increased osteoclast numbers already 3 months after surgery $[17,18]$. Another study reported the advantages of combining OVX and glucocorticoid administration over combining OVX and calcium restriction with a higher decrease of BMD of distal radius, distal tibia, and calcaneus (spongiosa by $25 \%$ and corticalis by $17 \%$ in the former group and 10 and 5\%, respectively, in the latter) [19]. Combining all 3 measures led to the most pronounced reductions (60 and $25 \%$ ). When using corticosteroids, the disadvantage of immunosuppressive side effects causing local and/or systemic opportunistic infections [20] and of hampering osteoimmunological analyses has to be kept in mind.

Sows seem to differently handle loss of ovarian function and nutritive calcium shortage with respect to bone morphology, but also their cellular immune system gives no evidence of being affected by these measures. This is another difference to postmenopausal women, whose $\mathrm{T}$ cells have been shown to be activated as a consequence of increased IFN- $\gamma$, TNF- $\alpha$, and RANKL synthesis [21]. Also, postmenopausal women have been shown to harbor higher levels of $\mathrm{CD} 8^{+} \mathrm{CD} 57^{+}$cells and to suffer from a proinflammatory state $[22,23]$, none of which has been observed in our model.

Another way to possibly achieve an osteoporosis-like phenotype in adult sows could be glucocorticoid treatment with all the disadvantages discussed above. Glucocorticoid-induced osteoporosis has already been shown as an option in the porcine model, albeit again minipigs have been used for these experiments.
Scholz-Ahrens and colleagues [24] induced an osteoporotic phenotype in adult (30 months old) primiparous Göttingen minipigs by daily oral prednisolone treatment at a dose of $1 \mathrm{mg} / \mathrm{kg}$ for 2 months with a reduction of this dose to $0.5 \mathrm{mg} / \mathrm{kg}$ thereafter until the end of the experiment, which was after 8 months in the short-term group and 15 months in the long-term group. In the short term, glucocorticoids reduced BMD at the lumbar spine by $48 \mathrm{mg} / \mathrm{cm}^{3}$ from baseline, whereas in the control group reduction was $12 \mathrm{mg} / \mathrm{cm}^{3}$. These changes were also evidenced by plasma BAP levels, which decreased significantly in the glucocorticoid group. In the long term, the loss of BMD became more pronounced, and bone mineral content, trabecular thickness, and mechanical stability tended to be lower compared with the control group. There was a negative association between the cumulative dose of glucocorticoids and BMD, which could be traced back to impaired osteoblastogenesis.

The present study has 2 major limitations. First, we analyzed only 8 sows per group. This small number is a consequence of the animals' dimension with each sow weighing over $300 \mathrm{~kg}$. On the other hand, comparable large animal studies included even smaller numbers of pigs $[4,25]$. The second limitation is the crosssectional design instead of a longitudinal one, which was due to logistic reasons. One additional limitation is the impropriety of serum estrogen measurement for validation of successful OVX in the pig model, which in the case of large animal surgery might not be considered a serious drawback as the ovaries are clearly visible and of a comparably large size. The aforementioned ineligibility is due to the fact that on the one hand serum estrogens are below the detection limit in non-ovariectomized sows during diestrus and on the other hand this study gives evidence of extragonadal sexual steroid synthesis in ovariectomized sows. Nevertheless, the percentage of animals with a measurable systemic estrogen titer was significantly lower in the group of ovariectomized sows when compared to non-ovariectomized ones.

In conclusion, the skeleton of adult conventional sows is seemingly protected from effects of OVX and calcium shortage, which is a very interesting finding. Hence, these animals do not appear to be a suitable model for investigations concerning postmenopausal osteoporosis but could be used to identify factors that 
protect bone from calcium or sex hormone deficiency. Moreover, this study additionally provides valuable information about yet unknown physiological data on bone metabolism parameters in adult sows. At the moment we have to accept that bone of some species such as laboratory rodents reacts to generally accepted osteoporosis-inducing stimuli such as OVX and calcium shortage as would human bone, whereas the skeleton of other species, such as the adult pig, seems to be resistant to the development of osteopenia or osteoporosis. The skeleton of bears may serve as another contradictory example, as it remains unaltered in the context of immobilization during hibernation [26]. Future studies should focus on unraveling the endocrinological and perhaps immunological mechanisms, which function as protectors of bone mass and structure in these species.

\section{Acknowledgements}

$\nabla$

This study was supported by a grant from the Austrian Science Fund, Project No: P20337-B13. We thank Katharina Wahl for her excellent assistance.

\section{Affiliations}

${ }^{1}$ Clinic for Swine, University of Veterinary Medicine Vienna, Austria

${ }^{2}$ Department of Medicine III, Technical University of Dresden, Germany

${ }^{3}$ Institute of Medical Chemistry, University of Veterinary Medicine Vienna, Austria

${ }^{4}$ Institute of Parasitology, University of Veterinary Medicine Vienna, Austria

${ }^{5}$ Institute of Pathophysiology, Medical University of Vienna, Austria

${ }^{6}$ Institute of Animal Breeding and Genetics, University of Veterinary Medicine Vienna, Austria

${ }^{7}$ Institute of Lightweight Design and Structural Biomechanics, Technical

University of Vienna, Austria

${ }^{8}$ II. Medical Department, Krankenhaus der Barmherzigen Schwestern, Vienna, Austria

${ }^{9}$ Central Laboratory, University of Veterinary Medicine Vienna, Austria

\section{References}

1 Pietschmann P, Rauner M, Sipos W, Kerschan-Schindl K. Osteoporosis: an age-related and gender-specific disease - a mini-review. Gerontology 2008 ; 55: 3-12

2 Guidelines for Preclinical and Clinical Evaluation of Agents Used for the prevention or Treatment of Postmenopausal osteoporosis. Division of Metabolism and Endocrine Drug Products, Food and Drug Administration. 1994

3 Mori R, Kodaka T, Soeta S, Sato J. Preliminary study of histological comparison on the growth patterned of long-bone cortex in young calf, pig, and sheep. J Vet Med Sci 2005; 67: 1223-1229

4 Mosekilde L, Weisbrode SE, Safron JA, Stills HF, Jankowsky ML, Ebert DC, Danielsen CC, Sogaard CH, Franks F, Stevens ML, Paddock CL, Boyce RW. Evaluation of the skeletal effects of combined mild dietary calcium restriction and ovariectomy in Sinclair S-1 minipigs: a pilot study. J Bone Miner Res 1993; 8: 1311-1321

5 Scholz-Ahrens KE, Delling G, Jungblut PW, Kallweit E, Barth CA. Effect of ovariectomy on bone histology and plasma parameters of bone metabolism in nulliparous and multiparous sows. Z Ernährungswiss 1996; 35: 13-21

6 Rauner M, Sipos W, Pietschmann P. Osteoimmunology. Int Arch Allergy Immunol 2007; 143: 31-48

7 Allen MJ. Biochemical markers of bone metabolism in animals: uses and limitations. Vet Clin Pathol 2003; 32: 101-113

8 Sipos W, Duvigneau JC, Hofbauer G, Schmoll F, Baravalle G, Exel B, Hartl $R$, Dobretsberger M, Pietschmann P. Characterization of the cytokine pattern of porcine bone marrow derived cells treated with $1 \alpha, 25(\mathrm{OH})_{2} \mathrm{D}_{3}$. J Vet Med A 2005; 52: 382-387
9 Palme R, Möstl E. Biotin-streptavidin enzyme immunoassay for the determination of oestrogens and androgens in boar faeces. In: Görög S (ed). Advances of Steroid Analysis '93. Budapest: Akadémiai Kiadó; 1994;111-117

10 Sipos W, Duvigneau J, Sterz F, Weihs W, Krizanac D, Bayegan K, Graf A, Hartl $R$, Janata A, Holzer $M$, Behringer $W$. Changes in interleukin-10 mRNA expression are predictive for 9-day survival of pigs in an emergency preservation and resuscitation model. Resuscitation 2010; 81: 603-608

11 Sipos W, Duvigneau CJ, Hartl RT, Schwendenwein I. Exploratory reference intervals on hematology and cellular immune system of multiparous Large White sows. Vet Immunol Immunopathol 2011; 141: 307-311

12 Sipos W, Schmoll F, Stumpf I. Minipigs and Potbellied Pigs as Pets in the Veterinary Practice - a Retrospective Study. J Vet Med A 2007; 54: 504-511

13 Klopfenstein C, Farmer C, Martineau G-P. Diseases of the Mammary Gland. In: Straw BE, Zimmerman JJ, D'Allaire S, Taylor DJ (eds). Diseases of Swine. Iowa: Blackwell Publishing; 2006;57-86

14 Turner AS, Mallinckrodt CH, Alvis MR, Bryant HU. Dose-response effects of estradiol implants on bone mineral density in ovariectomized ewes. Bone 1995; 17: 421-427

15 MacLeay JM, Olson JD, Enns RM, Les CM, Toth CA, Wheeler DL, Turner AS. Dietary-induced metabolic acidosis decreases bone mineral density in mature ovariectomized ewes. Calcif Tissue Int 2004; 75: 431-437

16 Chavassieux P, Garnero P, Duboeuf F, Vergnaud O, Brunner-Ferber F, Delmas PD, Meunier PJ. Effects of a new selective estrogen receptor modulator (MDL 103,323) on cancellous and cortical bone in ovariectomized ewes: A biochemical, histomorphometric, and densitometric study. J Bone Miner Res 2001; 16: 89-96

17 Giavaresi G, Fini M, Torricelli P, Giardino R. The ovariectomized ewe model in the evaluation of biomaterials for prosthetic devices in spinal fixation. Int J Artif Organs 2001; 24: 814-820

18 Pogoda P, Egermann M, Schnell JC, Priemel M, Schilling AF, Alini M, Schinke T, Rueger JM, Schneider E, Clarke I, Amling M. Leptin inhibits bone formation not only in rodents but also in sheep. J Bone Miner Res 2006; 21: 1591-1599

19 Lill CA, Fluegel AK, Schneider E. Sheep model for fracture treatment in osteoporotic bone: a pilot study about different induction regimens. J Orthop Trauma 2000; 14: 559-566

20 Lill CA, Gerlach UV, Eckhardt C, Goldhahn J, Schneider E. Bone changes due to glucocorticoid application in an ovariectomized animal model for fracture treatment in osteoporosis. Osteoporos Int 2002; 13: 407-414

21 Pacifici R. Postmenopausal osteoporosis: how the hormonal changes of menopause cause bone loss. In: Marcus R, Feldman D, Nelson DA, Rosen CF. (eds). Osteoporosis. Amsterdam: Elsevier; 2008;1041-1054

22 Pietschmann P, Grisar J, Thien R, Willheim M, Kerschan-Schindl K, Preisinger E, Peterlik $M$. Immune phenotype and intracellular cytokine production of peripheral blood mononuclear cells from postmenopausal patients with osteoporotic fractues. Exp Gerontol 2001; 36: 1749-1759

23 Zheng SX, Vrindts Y, Lopez M, De Groote D, Zangerle PF, Collette J, Franchimont N, Geenen V, Albert A, Reginster JY. Increase in cytokine production (IL-1 $\beta$, IL- 6 , TNF- $\alpha$ but not IFN- $\gamma$, GM-CSF or LIF) by stimulated whole blood cells in postmenopausal osteoporosis. Maturitas 1997; 26: 63-71

24 Scholz-Ahrens KE, Delling G, Stampa B, Helfenstein A, Hahne HJ, Açil Y, Timm W, Barkmann R, Hassenpflug J, Schrezenmeir J, Glüer CC. Glucocorticosteroid-induced osteoporosis in adult primiparous Göttingen miniature pigs: effects on bone mineral and mineral metabolism. Am J Physiol Endocrinol Metab 2007; 293: E385-E395

25 Boyce RW, Ebert DC, Youngs TA, Paddock CL, Mosekilde L, Stevens ML, Gundersen HJG. Unbiased estimation of vertebral trabecular connectivity in calcium-restricted ovariectomized minipigs. Bone 1995; 16: 637-642

26 McGee LME, Wojda SJ, Barlow LN, Drummer TD, Castillo AB, Kennedy $O$, Condon KW, Auger J, Black HL, Nelson OL, Robbins CT, Donahue SW. Grizzly bears (Ursus arctos horribilis) and black bears (Ursus americanus) prevent trabecular bone loss during disuse (hibernation). Bone 2009; 45: 1186-1191 